\title{
Gender issues in project management: A subtlety
}

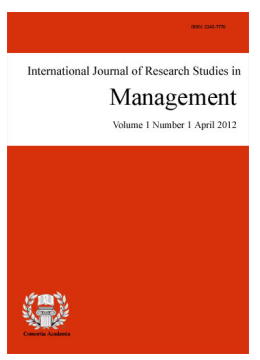

Pacha, Malyadri $\bowtie$

Principal, Government Degree College, Osmania University,India (drpm16@yahoo.com.in)

Banda, Sumana

Department of Management, JNT University, India (anda sumana@yahoo.com)

\section{Abstract}

There are 2 bottlenecks in the drive of literacy towards women empowerment. Classifying women in India into 2 economic categories, the lower socio-economic category is still struggling to establish a higher literacy rate amongst the girl child. In the upper strata, where education equality has been established, the concern is equality in the corporate world. The present paper is an attempt to analyze the impact of growing project management responsibilities on women. Have women in software project management shifted from this technical and marketing fronts to other soft skill departments to combat issues of domestic and corporate imbalance or have they stepped off from the corporate ladder! The paper tries to derive a pattern of both similarity and difference in the managerial competence of male and female managers in the technological domain and analyze the steps to arrive at the androgynous manager model.

Keywords: societal inequity; project management life cycles; crisis management; glass ceiling 


\section{Gender issues in project management: A subtlety}

\section{Introduction}

The establishment of Software business organizations in India has apparently wiped out the glaring gender discrimination in education and in employment in the corporate world. The government laws and increased societal awareness has ensured that the girl child is not denied entry into this world. However, beyond this point, discrimination against women lingers in a plethora of work practices and cultural norms that only appear unbiased. They are common and mundane and woven into the fabric of an organization's status quo-which is why most people don't notice them, let alone question them. But they create a subtle pattern of systemic disadvantage, which blocks all but a few women from career advancement (Meyerson \& Fletcher, 2000).

\section{What is gender?}

Technically, gender is not synonymous with women. It encompasses the learned behavioral differences between men and women in a given community or household, and the roles which are expressed according to sex in women's and men's actions, tasks, and responsibilities (Gawler, n.d.). Dealing with gender issues does not mean simply providing a loan or management training to a women's forum, but rather understanding and working with the social construction of gender and the assignment of specific roles, responsibilities, and expectations of women and men. It means working together with both men and women, first to understand, then to reflect on traditional stereotypes, and even taboos. Achieving gender equity is a precarious process, which can easily backfire, especially in the hands of an over-eager extension worker who has put on her heavy boots in the hope of getting quick results. It is a process that requires skill, sensitivity, and patience.

Equality between men and women is both a human right and a development goal. It is now widely accepted that gender equality and women's empowerment are fundamental cornerstones for achieving development results. To quote a few of the norms which cause gender inequality and create lacunae in women from continuing in the managerial positions in a software organization are:

$>$ meetings which routinely and regularly spill over time,

$>$ constantly shifting deadlines,

$>$ crisis management that demands immediate attention,

$>\quad$ managers are expected to be available at all times to attend delayed or emergency meetings.

All of the above affect both men and women but more so the women who has to bear a disproportionate amount of responsibility for home and family and thus have more demands on their time outside the office.

\subsection{The blame game}

Who is to be blamed for this societal inequity?

In urban India, religious and cultural traditions do not majorly influence gender discrimination in education like in other developing countries (Dubel, Macdonald, \& Sprenger, 1999). There has been a paradigm shift from the girl child choosing humanities and the boy child studying mathematics and sciences to the girl child also opting for the technical study groups. This graph has no change keeping the girl child on equity with boy child in the higher education and corporate entry criteria level (Subrahmanian, 2005). Selection, placement and promotion make no parity check on gender. So, now, where is the hitch? It creeps in slowly at the middle management level when the woman has more burdens on the societal and home front also. 


\subsection{Bottleneck in the cycle of literacy and women empowerment}

Classifying women into 2 economic categories, the lower socio-economic category is still struggling to establish a higher literacy rate amongst the girl child. Education of the girl child and empowering the women to have economic independence is a continuous cycle. In the upper strata, where education equality has been established, the concern is gender equity in the corporate world. This paper deals with those enterprising women who want to sketch a career for themselves, who struggle hard to acquire the necessary skills through education to make it to the threshold of an organization, more particularly, the IT Industry. The establishment of Software business organizations in India has wiped out the glaring gender bias in the corporate world. The government laws and increased societal awareness has ensured that the girl child is not denied entry into this world. Today, discrimination against women lingers in a plethora of work practices and cultural norms that only appear unbiased. They are common and mundane, woven into the fabric of an organization's status quo, which is why most people do not notice them, let alone question them. But they create a subtle pattern of systemic disadvantage, which blocks all but a few women from career advancement (Meyerson \& Fletcher, 2000).

\subsection{Barriers which a woman faces while climbing up the corporate ladder}

We can echo that management means directors and managers who have the power and responsibility to make decisions to manage an enterprise. Hence management comprises of the interlocking functions of formulating corporate policy and organizing, planning, controlling, and directing the firm's resources to achieve the policy's objectives (Luthra, 2007-2011). Applying this theory to the household tasks performed by a middle-aged home-maker, we can draw a one-one line mapping from the definition to the home-maker's tasks of providing a comfortable place of living by managing machines and manual labor within the financial budget of the family. Multi-tasking seems to be an innate ability of any average Indian woman. Hence, women assumed the dual role of managing office and home. However, the difference between a male manager and a female manager is that the male manager manages the office while it is a dual multi-tasking management role for the woman; she seems to be carrying too much on her plate. If there is some load sharing at the home front, then there need not be any load shedding on the official front for the women. Another subtlety is the emotional dissatisfaction among men who are able to accept women as colleagues but not the wife as an earning member or more so as a boss. How peaceful is the home where the wife's purse weighs more? Is the lady of the house herself comfortable with such a scenario? These issues come under the ambit of society and require universal processes for upheaval.

Analysts have argued that organizations themselves (their structures, ways of working, decision-making, and institutional 'culture') can have significant gender overtones. For example, they point out that organizational expectations imply that workers have few or no family responsibilities (that they can be away from home for significant periods of time or that they can work late into the night) (Gawler, n.d.). With this expectation, we can see that project execution phase which involves junior level men and women does not impinge on the family life of a woman. With the increasing age, a woman's responsibility at home increases due to marriage, children and household chores in tandem with the ascent to the management levels at the official front and hence the demand in time from both sides does not balance.

$>\quad$ Spill over meetings may clash with a child's school program

$>\quad$ constantly shifting deadlines does vie with family time

$>$ crisis management at both sites demands $24 * 7$ attention (priority being office)

$>\quad$ managers are expected to be available at all times to attend delayed or emergency meetings and the same as wives / mothers are expected to be available at all time at home to attend to the sick or visiting relatives 
These issues which have to be constantly balanced by all working people are more evidently imbalanced for women in the software managerial positions. Hence, women in software project management prefer to shift to other soft skill departments from technical and marketing fronts to combat these issues of imbalance or step off from the corporate ladder!

\subsection{How then are we to challenge the belief that balancing home and work is fundamentally a woman's}

problem?

This calls for a review of our social fabric. How do we weave it to suit our modern information and technology era? In the stone age era, where hunting required physical power, the woman decided to stay at home to tend to cattle and home and allowed the man to go out. Now, in this new era where man has invented simple to complex machines to minimize physical work and where mind power commands supremacy compared to physical power, both genders can vie with each other to step outside to prove their talent and hence both should share the family responsibility equally.

\section{Project management model skewed}

In a typical Indian software organization, the work product is a project execution. A separate project team is charted out for each project which involves either development and implementation or implementation and maintenance or implementation and handing-over of a software product for a particular client. These project teams vary in size in proportion to the size of a project which depends on the number of work items and the completion time. Each project is headed by a project manager and every project is subjected to follow the guidelines established in project management by their respective quality departments.

Project management life-cycles need to be explored and synergized with innovative inclusive models. A typical Project Management Life Cycle has four phases: Initiation, Planning, Execution and Closure (PMBOK, n.d.).

The Project Initiation Phase is the 1st phase in the Project Management Life Cycle, as it involves starting up a new project. A new project can be started by defining its objectives, scope, purpose and deliverables to be produced. The project team is formed; Project Office is setup and reviewed, to gain approval to begin the next phase.

The Project Planning Phase is the second phase in the project life cycle. It involves creating of a set of plans to help guide the team through the execution and closure phases of the project.

The Project Execution Phase is the third phase in the project life cycle. This phase involves development of physical project deliverables and presenting them to customer for signoff. To enable better monitoring and control of the project during this phase, a range of management processes are implemented. These processes help to manage time, cost, quality, change, risks and issues. They also help to manage procurement, customer acceptance and communications.

The Project Closure Phase is the fourth and last phase in the project life cycle. Project Closure involves handing over the deliverables to the customer, passing the documentation to the business, releasing staff and equipment, and informing stakeholders of the closure of the project.

The project execution phase involves the entry level employees in the organization called as programmers or software engineers. The work load does not impinge on the family life of the individual since most of the individuals engaged in this phase would be fresh graduates. Apart from the project execution phase the remaining phases have a high degree of responsibility and involve the project manager. The ratio of men to women increases very high as the career ladder ascends and as their involvement increases in project phases such as initiation, planning and closure. What seems an escalator for both men and women at the time of joining up 
until the middle management level may continue to be the same for men, but will become a sticky ladder for women? Hence the progress is slow or nil in the middle management - senior management bracket in the case of women.

\subsection{Glass ceiling or The Sticky Ladder?}

Even though the metaphorical glass ceiling (Robert Reich, 1995) does not apply to the Indian IT industry we hardly find women at the top echelons. Glass ceiling in IT industry was persistent in USA about a decade back. Accenture (2008) examined the worldwide perception of the unofficial barrier to upper management that certain groups particularly women, may find difficult to cross. They analyze that successful managers of both genders have many common similarities and one striking difference that women need more support from government and society to advance in career. Their key analysis is

$>$ Gender is no longer believed to be a career-limiting factor

$>\quad$ Female executives believe that companies are doing a better job than society in general to promote equality. So, individuals and organizations have ensured that the glass ceiling no longer exists.

$>\quad$ Why then has the climb for the women on the corporate ladder slowed down after reaching the middle management level?

$>\quad$ Where is the career escalator leading women to?

$>\quad$ Has the corporate ladder become sticky now at senior levels?

Sticky ladder is a term used to describe women's struggle to reach the top of the corporate ladder. This term describes theory that women are not incapable of reaching the top; they just get "stuck" on the middle rungs of the ladder.

There has been a paradigm shift from the girl child choosing humanities and the boy child studying mathematics and sciences to the girl child also opting for the technical study groups. This curve keeps on increasing keeping the girl child at par with boy child on the higher education and corporate entry criteria level. Selection, placement and promotion make no parity check on gender. So, now, where is the hitch? It creeps in slowly after the middle management level when the woman also has more burden on the societal and home front. So, the responsibilities at home and office increase in tandem.

If the glass ceiling seems to still pervade, it does not mean that, women have climbed and hit a ceiling even before reaching the senior management level, it only means that they are stuck up on the corporate ladder and are not able to reach the senior management chairs. It has more factors external to the corporate structure. To analyze the root cause we need to examine the glass ceiling under a new light.

\subsection{The androgynous project management model}

In all societies, men and women are assigned tasks, activities and responsibilities according to their sex. The gender division of labor varies from one society and culture to another, and in each culture, it also changes with external circumstances and over time. Because in most societies, gender power relations are skewed in favor of men, specifically, regarding domestic work, different values are ascribed to men's tasks and women's tasks. However, IT corporate scenario is not influenced by these parameters.

All managers irrespective of gender hope to hone the best skill sets and drivers to help them climb the career ladder and achieve their goals and satisfy their aspirations. Project management life-cycles mentioned above need to be explored further and synergized with innovative inclusive models. To arrive at an androgynous management model let us examine the strengths and the show-stoppers of aspiring women senior managers. 
Pacha, M. \& Banda, S.

3.3 Strengths of the current project management model

$>\quad$ Men and women are both equally ambitious

$>$ Assertive

$>\quad$ Have equal fire-fighting skills

$>$ Have similar social background and educational background

\subsection{Show-stoppers in the current project management model}

$>$ Female executives when younger advance more rapidly than their counterparts

$>$ Family commitment is expressed by women more than men

$>$ Men network more than women within the organization

$>\quad$ Females focus less on creating internal visibility

\subsection{The Blame Game}

So, whom do we blame for this sticky corporate ladder? Gender roles are socially determined and can be affected by factors such as education or economics. Gender roles may vary widely within and between cultures, and often evolve over time. Men, then, are not to be blamed for the pervasive gender inequity in organizations today-but neither are women (Meyerson \& Fletcher, 2000). Upon analyzing the various feeders for the sticky ladder, we need to propound an action plan at the individual, corporate, government and societal levels which will ensure wholesome economic growth. We need to formulate rules and regulations for binding all involved to ensure the congenial and economic growth of the whole society in general.

\section{Drivers/suggestions for an inclusive growth}

After analyzing the issues related to growth of women in the corporate IT world, we can classify the same into organizational, societal, governmental and individual. There are some pointers which the government and organizations are to a large extent concerned with, however, to a large extent there are systemic changes which have to be acted upon by each individual and society in general.

\subsection{Organizational}

From an organizational point of view, women are liabilities because of their domestic responsibilities or they prioritize home to late office hours. Their commitment to marriage and family prevents their entry into corporate boardrooms. The fact that they might get in the family way also increases apprehensions about the long holidays this would entail.

Why should the organization encourage the professional growth of women?

$>$ Innovation is the main driver for organizational progress and this requires diverse talents and approaches which may become stereotypical in a group of same gender.

$>\quad$ On the soft skills, women show more emotional quotient and hence can bind teams and she pledges her loyalty for the organization.

$>\quad$ Since the duty of an organization is to make profits, irrespective of which it employs and if the same profits can be increased with the employment of capable women, then, the organization will anyway not think twice. 


\subsection{Government}

Why should the government encourage the professional growth of women? The answer is that we can make use of the nation's entire elite human capital. Norway enforced a law that by January 2008 in all listed companies, $40 \%$ of the non-executive directors must be females and the companies have achieved their targets. Any initiative should have a government legislative interference to be successful. Other pointers to the government are (Robert, 2008).

$>$ Co-ordinate with the organizations to plan and introduce parental leave in addition to maternity leave

$>\quad$ Formulate legislative laws to create quotas for women in middle management levels and senior management levels as has been done in education system

\subsection{Society}

Women are the ones who lead the next generation, and are the best peers for their progeny. In whatever role they chose to be as a home maker or a professional, society needs to kindle in them a broader vision and an in-depth insight. Stereo-typical roles should not be in-grained into the children based on their gender. All the women in our country must realize the importance of dual roles leading to financial freedom, which will go a long way in ending the unquestioned hereditary oppressiveness. This will cyclically induce an intention to create wealth. Once this equality is induced into the system from childhood, equality will become a way of life while sharing domestic load after marriage.

Why should the society encourage the professional growth of women? It is about changing attitudes and mind-sets to create wholesome growth of the entire society and to increase of economic growth of the nation. Society should in general be open and supportive to women's rights groups in encouraging the cause for equality at home. This endeavor is to balance the chances of success for both genders in the IT industry. Women are very keen on setting high value systems. Awareness needs to be created in men as to the need of their involvement at office and home in-order to create a better world for the next generation.

\subsection{Individual}

Gender planning is not an end in itself (Moser, 1993). The following are pointers to corporate women trying to reach the top echelons of the organization and ultimately empowerment and emancipation:

On the domestic front,

$>\quad$ women need to remember that they are moulding the economy of tomorrow so they need to inculcate a proper equality based value system in their children irrespective of the gender

On the corporate front,

$>\quad$ Network within the organization and with senior leaders in the industry

$>\quad$ Seek mentors and be in-turn a mentor to help others in knowledge transfer

$>\quad$ Seek internal visibility

$>$ Take risks

\section{Conclusion}

Analyzing the Indian IT Software industry, we notice that the work environment is virtually grouped into project teams. Each project team executes the job requirement of the client in accordance with the job contract 
made between the client and the organization. Each project follows an independent hierarchical execution and reporting structure. The project team has a group of programmers at the bottom of the hierarchy. They report to project leaders who in turn have to escalate issues to a project manager. Project managers have minimum 5 years of experience and they in turn report to senior management regarding the project costing, completion schedules and resource re-allocation. At the level of the programmer and team leader, men and women face equal opportunities and threats. They are rated equally according to their technical potential and promoted in lieu. At the threshold of project manager role sweeps in the gender differentiator as mentioned above, where women have to face more domestic responsibilities. Hence, their managerial opportunities face the brunt and they force themselves to make choices based on their domestic priorities.

While we cannot change the historical baggage with regards gender we can develop policies at management level that will be the building blocks for gender mainstreaming throughout the lifetime of project management and beyond. Indeed gender mainstreaming comprising of orderly integration of gender equality into all policies and programs is innate within the organization. To a large extent there are systemic changes which have to be acted upon by each individual and society in general.

\section{About the authors:}

Dr. P. Malyadri has got 27 years of experience of Teaching, Research, Administration, Training and consultancy. A prolific writer; Dr. Malyadri has authored 4 Books and 64 research papers on Banking, Rural and economic development issues in various National and International journals of repute. He has presented several research papers in around 80 National and International seminars and conferences. $\mathrm{He}$ is on the International Editorial advisory boards as a Member in 74 International Peer reviewed journals published from Canada, USA, U K ,Taiwan, Czech Republic, Italy, Turkey, Dubai, Philippines, Australia ,Bangladesh, Romania, Pakistan. Iran, Africa, Nigeria, Berlin, Indonesia, Singapore, and many others; and 30 national journals of repute. Dr.Malyadri carried out two Major Research Projects sponsored by the UGC, New Delhi. He is a recognized Research supervisor to guide M.Phil. and Ph.D. students in the Departments of Commerce and Business Management, Osmania University and was awarded 3 Ph.D.'s and 22 M.Phil.'s under his guidance. He served as Program officer of the National Service Scheme for 5 years and conducted several programs and received outstanding awards. Presently he is serving as the Principal; Osmania University affiliated Government Degree College for the last 3 years. He received several outstanding awards for his academic achievements. Dr. Malyadri is State level Best Teacher awardees in the year 2008, honored by Government of Andhra Pradesh. His current research interests include CRM, Bank Marketing, and Micro Finance. Rural Development, Human Resource Management, Entrepreneurial development.

Ms. B. Sumana has over a decade of experience in International Software Consultancy firms, with focus on application consulting and projects management for leading firms in U.S.A., U.K. and APAC. Currently pursuing Ph.D doctoral program in IT Management, the author holds a bachelor's degree in Maths \& Computer Science from Madras University, Master Diploma in Business Administration from Symbiosis Institute of Management Studies and Master of Business Administration from Sikkim Manipal University. Ms.Sumana has made paper presentations in several national seminars and conferences. She is on the technical advisory board of a prestigious international science and social science journal from USA. She has taken up a project entitled "Women leadership in Software Industry - Prospects and Problems", for her Doctoral degree from JNT University, Hyderabad. Her current research interests include Human Resource Management, IT Management and women empowerment. 


\section{References:}

Accenture. (2008). Glass ceiling still barrier. Retrieved May 15, 2012, from http://www.hrmguide.net/canada/diversity/accenture-equality.htm

Dubel, I., Macdonald, M., \& Sprenger, E. (1999). Gender and organisational change: Bridging the gap between policy and practice ( $2^{\text {nd }}$ ed.). Amsterdam: Royal Tropical Institute.

Gawler, M. (n.d.). Is your project adequately addressing gender issues? Retrieved May 15, 2012, from http://www.artemis-services.com/downloads/gender-review-questions.pdf

Luthra, V. (2007-2011). Management definitions, web finance incorporation. Retrieved May 15, 2012, from http://www.businessdictionary.com/definition/management.html

Meyerson, D., \& Fletcher, J. (2000). A modest manifesto for shattering the glass ceiling. Retrieved May 15, 2012, from http://hbr.org/2000/01/a-modest-manifesto-for-shattering-the-glass-ceiling/ar/1

Moser, C. O. N. (1993). Gender planning and development: Theory, practice and training. London and New York: Routledge.

PMBOK. (n.d.). Project management life cycle. Retrieved May 15, 2012, from http://www.mpmm.com/project-management-methodology.php

Robert Reich, B. (1995). Good for business: Making full use of the nations' human capital. Retrieved May 15, 2012, from http://www.dol.gov/oasam/programs/history/reich/reports/ceiling.pdf

Roberts, Y. (2008). You're fired! Retrieved May 15, 2012, from http://www.guardian.co.uk/lifeandstyle/2008/mar/06/women.discriminationatwork

Subrahmanian, R. (2005). Gender equality in education: Definitions and measurements. International Journal of Educational Development, 25(4), 395-407. 
Pacha, M. \& Banda, S. 